\title{
Geophysical exploration of castle remains in Barwałd Górny (near Kalwaria Zebrzydowska, Poland) using electrical resistivity tomography (ERT) with assistance of depth of investigation index (DOI) method.
}

\begin{tabular}{|c|c|}
\hline $\begin{array}{l}\text { Michał Glazer } \\
\text { Damian Kula }^{2} \\
\text { Robert Saternus }^{2} \\
\text { Paweł Lewicki }^{3}\end{array}$ & $\begin{array}{l}\text { IDepartment of Geomorphology, Faculty of Earth Sciences, } \\
\text { University of Silesia, Będzińska Str.60,41-200 Sosnowiec, } \\
\text { m.glazer@o2.pl } \\
{ }^{2} \text { Student Science Society of Geophysicists PREM, Faculty of Earth } \\
\text { Sciences, University of Silesia, Będzińska Str. 60,41-200 Sosnowiec, } \\
\text { damiankula@outlook.com, } \\
\text { robert.saternus@gmail.com } \\
{ }^{3} \text { Archaeology Student's Club at Jagiellonian University, Gotębia Str. } \\
\text { 11,31-007Kraków, } \\
\text { pawel.lewicki13@gmail.com }\end{array}$ \\
\hline
\end{tabular}

\begin{abstract}
In March of 2014 at ruins of the $14^{\text {th }}$ century castle, situated at the top of Mount Żar in Małopolska region, Poland, geophysical surveys were performed. Surveys were planned to investigate remains of the castle that could remain in the ground. Electrical Resistivity Tomography method was used there. In the paper 4 sections have been presented. During interpretation, as the supporting method, maps of Depth-of-Investigation (DOI) index have been used. Results of the surveys can point out potential remains of the castle walls and ruins of buildings that were situated in the stronghold.
\end{abstract}

Key words: Electrical resistivity tomography (ERT), archeology, depth of investigation index (DOI),

DOI: $10.2478 /$ ctg-2014-0019

Received: $30^{\text {th }}$ June, 2014

Accepted: $4^{\text {th }}$ September, 2014

\section{Introduction}

Nowadays archeology use more and more often geophysical methods for identification of geological medium before archeological excavations (Poręba, Zuberek 2007). One of this methods, very useful for archeologists, is the method of electrical resistivity (Griffiths, Barker 1994), in particular electrical resistivity tomography (resistivity imaging), which is outstanding due to for example: wide intervals of depth range (from several to several hundred meters) or to the precise map of geological center research (Rudzki 2002).
Mainly these features brought on to choose an electrical resistivity tomography (ERT) to run geophysical project which purpose was the identification of the $14^{\text {th }}$ century castle in Barwałd's remains, such as dungeons, foundations wall or underground water tank. Thereby, the main task of geophysical recognizing was to determine places, where archeologists should start excavations in the future.

The research was performed on the spot of the medieval castle in the Barwałd Górny village (near Kalwaria Zebrzydowska), which was built on the top of Mount Żar $(527 \mathrm{~m}$ 
above sea level. Nowadays this area belongs to Commune Stryszów which is exactly marked on Fig. 1. Geographically this place belongs to Wielicki's foothill (Czeppe Z., German K., 1981). In terms of geology, Żar's hill is built of Carpathian flysch, consisting of repeated layers of sandstone and shale (Siemionow 1984).

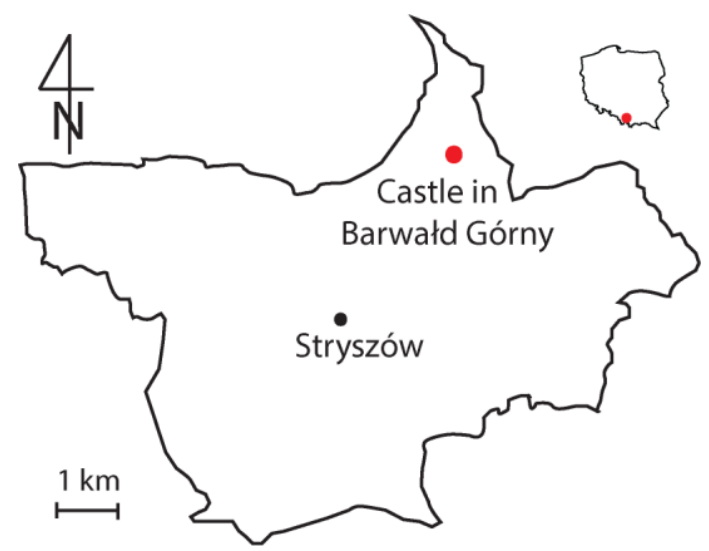

Fig.1. Approximate location of Stryszów.

To this day, only vestigial remains of old fortified stone wall are left on this spot. The rest of castle structures - dungeons or foundations are underground. Furthermore, the topography remained perfect - an oval plateau with dimensions $20 \times 50 \mathrm{~m}$ is surrounded by
10 meter high fosse and 6 meter long bulwark (Leńczyk 1983) (Fig. 2).

\section{Archaeological and historical review}

The medieval castle in Barwałd was probably built by duke Jan I in the middle of $14^{\text {th }}$ century. It was situated almost on the top of Mountain Żar near Kalwaria Zebrzydowska (Southern Poland). This location was chosen to protect the eastern borderland of the duchy of Oświęcim in case of the attack from the Polish Kingdom. The first written source about the stronghold informed us that in year 1440 dukes of Oświęcim gave the Barwałd castle to the king of Poland. After that, the stronghold changed owners many times. In 1475 the castle was given to Piotr Komorowski, who tried to transfer his lands in Poland with the king of Hungary to get back his castles in Orava. To protect polish influences in this territory Kazimierz IV, the king of Poland sent in 1477 Jakub Dębiński with the army to capture and destroy all Komorowski's fortress. He took over and ruined the castle in Barwałd and this was probably the end of its functioning (Sikora 1980).

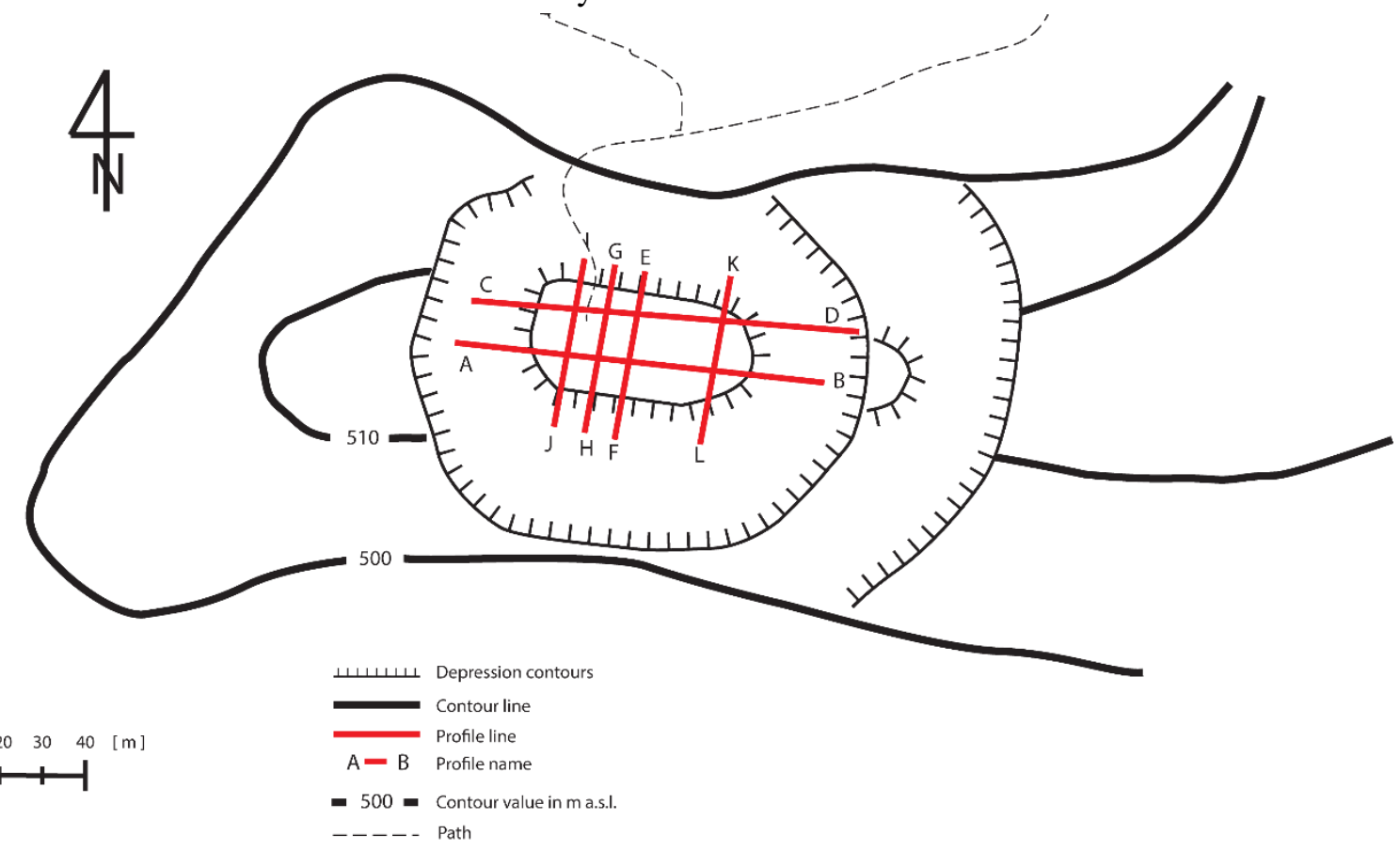

Fig.2. Arrangement of profile lines in ruins of Barwałd Castle. 
Unfortunately, the state of research about the castle is unsatisfactory. There was no excavation on this site so it is impossible to check the information from the written sources. Until now there is only the simple plan of the castle hill and short notices in scientific literature (Kajzer et al. 2001). The project of non-destructive research of the ruins can bring a lot of information about this medieval stronghold.

Water was always the necessary condition for the human existence. For this reason strongholds often were situated near rivers or lakes. If the castle stood on the rocky mountain top, builders tried to provide water by constructing wells or cisterns (Kołodziejski 1994; Kajzer et al. 2001). Perhaps similar structures were functioning in Barwałd fortress.

Visible remains of walls in the eastern part of the castle suggest that the castle was fortified by two lines of curtains. It is also possible that in this area could stand the gatehouse with the bridgehead for the drawbridge. The example for this kind of defensive structures in strongholds of duchy of Oświęcim is the Wołek castle in Kobiernice. During excavations on this site, relicts of many constructions were discovered. This allowed to create a plan of the castle with two lines of curtains and the gatehouse with the stone bridgehead (Reyniak 1997).

\section{Methodology}

Resistivity imaging surveys have been performed using ABEM Terrameter LS on two cables with 21 take-outs. On investigation site 6 profile lines have been designated. Two long ones with the electrode spacing $2.5 \mathrm{~m}$ and four short, perpendicular to previous ones, with $1 \mathrm{~m}$ spacing. Long profiles have been placed along the extended axis of the oval plateau. Their purpose was to acquire information on archeological objects as well as geological structure of the hill. Whereas short profiles were designed only for the first purpose, crossing the areas indicated by archeologists as the most interesting. To take into consideration high denivelation on profile lines it was necessary to carry out measurements with leveling instrument. On each survey site Wenner-Schlumberger and dipole-dipole measurements protocols have been used. The applied current intensity was in the $100-200$ $\mathrm{mA}$ range. Due to scope of this article only four chosen profiles, with the electrode array that in the best way helped to fulfill their purposes, are presented.

The inversion of resistivity data was carried out in Res2Dinv x64 ver. 4.03.13 software. By definition bodies with sharp boundaries have been seek. That is why L1 norm smoothness-constrained optimization method, which tends to minimize the absolute changes in model resistivity values as also the absolute difference between the measured and calculated apparent resistivity values, has been applied (Loke et. al., 2003; Loke, 2013). Because the large resistivity variation near surface were present, all models have been discretized by the model cells with widths of the half of unit electrode spacing.

To estimate the reliability of prepared resistivity models, depth of investigation (DOI) index method has been used. It is based on comparison of two resistivity models originates from the same data set and created by usage of different reference models in inversion process. It was firstly introduced by Oldenburg and Li (1999) and successfully used by Marescot et al. (2003) for mountain permafrost studies. Recovered DOI value for a single model cell according to Oldenburg and Jones (2007) with modification from Deceuster et al. (2014) is given by:

$R_{A B}(x, z)=\frac{\left|\log _{10} q_{A}(x, z)-\log _{10} q_{B}(x, z)\right|}{\left|\log _{10} q_{A}-\log _{10} q_{B}\right|}$ 
where:

- $q_{A}(x, z)$ and $q_{B}(x, z)$ are the model cell resistivities obtained from the first and second inversions,

- $q_{A}$ and $q_{B}$ are the first and second uniform reference models resistivities values.

Application of the logarithm stabilizes the obtained DOI. In this paper authors decided to perturbate reference models to values of ten times and one tenth of average apparent resistivity measured at the investigation site. This is known as a two-sided difference (Marescot et al., 2003). DOI index values will be near 0 in regions strongly dependent on data while it will rise up to 1 where obtained resistivity value for model cell depend strongly on objective function parameters (Oldenburg and $\mathrm{Li}, 1999)$. To ensure that the data have minimal information about the resistivity of the cells in the lowest layer i.e. DOI index will close to 1 , the depth range of the inversion models has been extended 3.5 times the median depth of investigation of largest array spacing used. Furthermore, discretization with each model cells of the same width has been extended to ends of survey line. DOI index obtained in this manner have been processed in Surfer 8 software to create DOI index maps that have been overlap with generated resistivity cross sections.
As a value of DOI index that above which we have to be very cautious with interpretation of resistivity models Oldenburg and Li (1999) firstly suggested to be 0.1 or 0.2 . Caterina et al. (2013) proposed to use the maximum gradient line of the DOI rather than a predefined value. On the other hand Oldenburg and Jones (2007) preferred index of 0.3. Here a cut-off value of 0.2 has been used.

\section{Results}

Average resistivity of all profiles varies from about $50 \Omega \mathrm{m}$ up to $400 \Omega \mathrm{m}$. Resistivity of high resistivity anomalies starts in most cases from about $600 \Omega \mathrm{m}$ and exceeds $3000 \Omega \mathrm{m}$ on profile KL. Low resistivity anomalies are below $50 \Omega \mathrm{m}$.

Resistivity of most of the area of $\mathrm{AB}$ profile (Fig. 3) varies from $50-350 \Omega \mathrm{m}$. In general, there can be seen a massive anomaly of 200-300 $\Omega \mathrm{m}$ that starts at 7 meter under the surface and continues toward the bottom of profile. There is also lower resistivity layer above and few low resistivity zones just below the surface of the ground. There can be also seen a few anomalies at both ends of profile and at $30 \mathrm{~m}$ and $80 \mathrm{~m}$ of the profile. Resistivity of those anomalies is higher than $400 \Omega \mathrm{m}$.

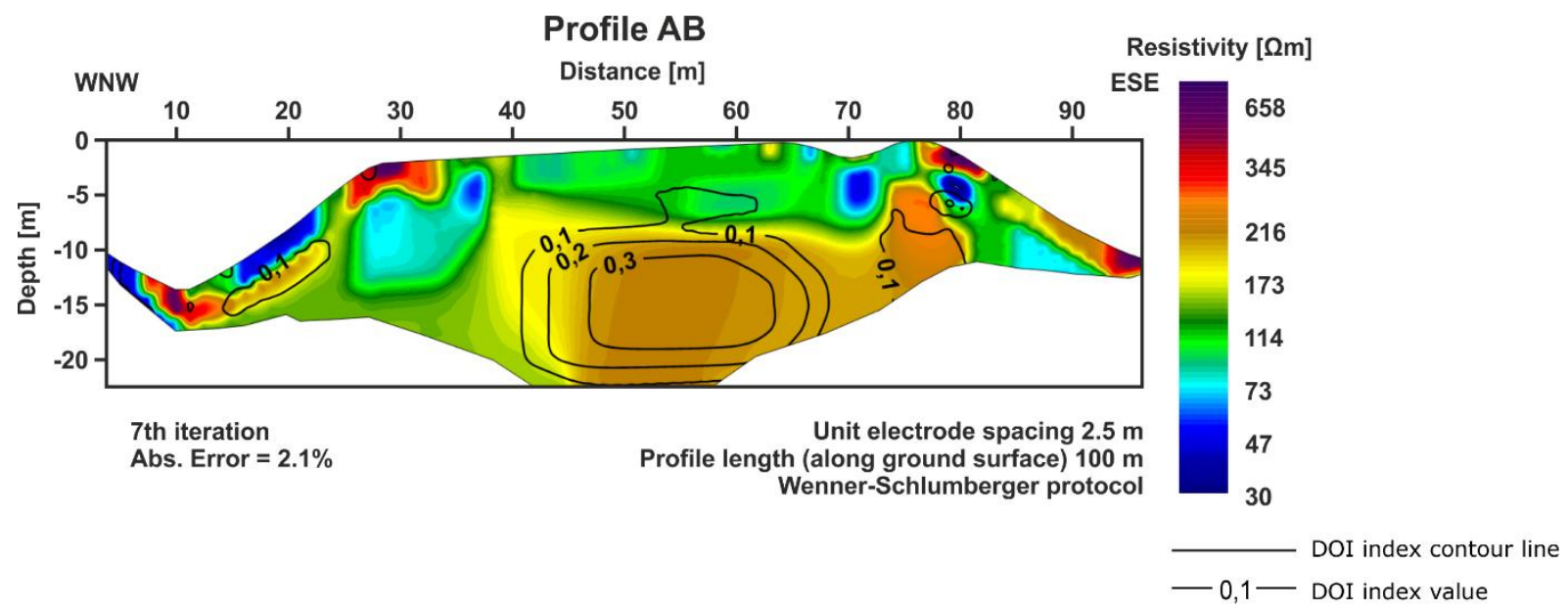

Fig.3. Resistivity cross-section from profile AB, overlapped with DOI index map. 
Profile GH shown on fig. 4 is in general covered with low resistivity values between $75 \Omega \mathrm{m}$ and $250 \Omega \mathrm{m}$. There are two major areas in the center of the profile. Resistivity of the first area is varying around $80 \Omega \mathrm{m}$ and is located around $13 \mathrm{~m}$ of the profile, second area is located to the SSW from the first zone. Its resistivity oscillates around $120 \Omega \mathrm{m}$. There can be also seen few high resistivity anomalies at both ends of the profile. Resistivity of those zones exceeds $350 \Omega \mathrm{m}$. In the center of profile, just below surface, there are present few small low resistivity zones.

Resistivity of profile IJ fig. 5 is more homogeneous. In general there can be seen low to medium resistivity area in the center of profile that is surrounded with areas that's resistivity rises towards both ends of the profile. In the center there can also be seen one low resistivity anomaly of $20 \Omega \mathrm{m}$. To the SSW of it there is significant increase of resistivity value up to $300 \Omega \mathrm{m}$. At slopes at both ends of profile there can be seen high resistivity anomalies of around $400-1500 \Omega \mathrm{m}$.

On fig. 6 is shown profile KL that is very differentiated. RMS error of that model after 12 iterations of inversion was still $9,6 \%$. The central part of the profile is covered by area of medium resistivity. Just below the surface there are present large high resistivity anomalies. The one of biggest area starts at NNE end, continues toward the center and ends at $15 \mathrm{~m}$ of the profile. There is another high resistivity anomaly at top of slope at SSW end of profile. Resistivity of both anomalies is higher than about $600 \Omega \mathrm{m}$. At SSW end of the profile there are also present a few smaller points where resistivity drops to $20 \Omega \mathrm{m}$.

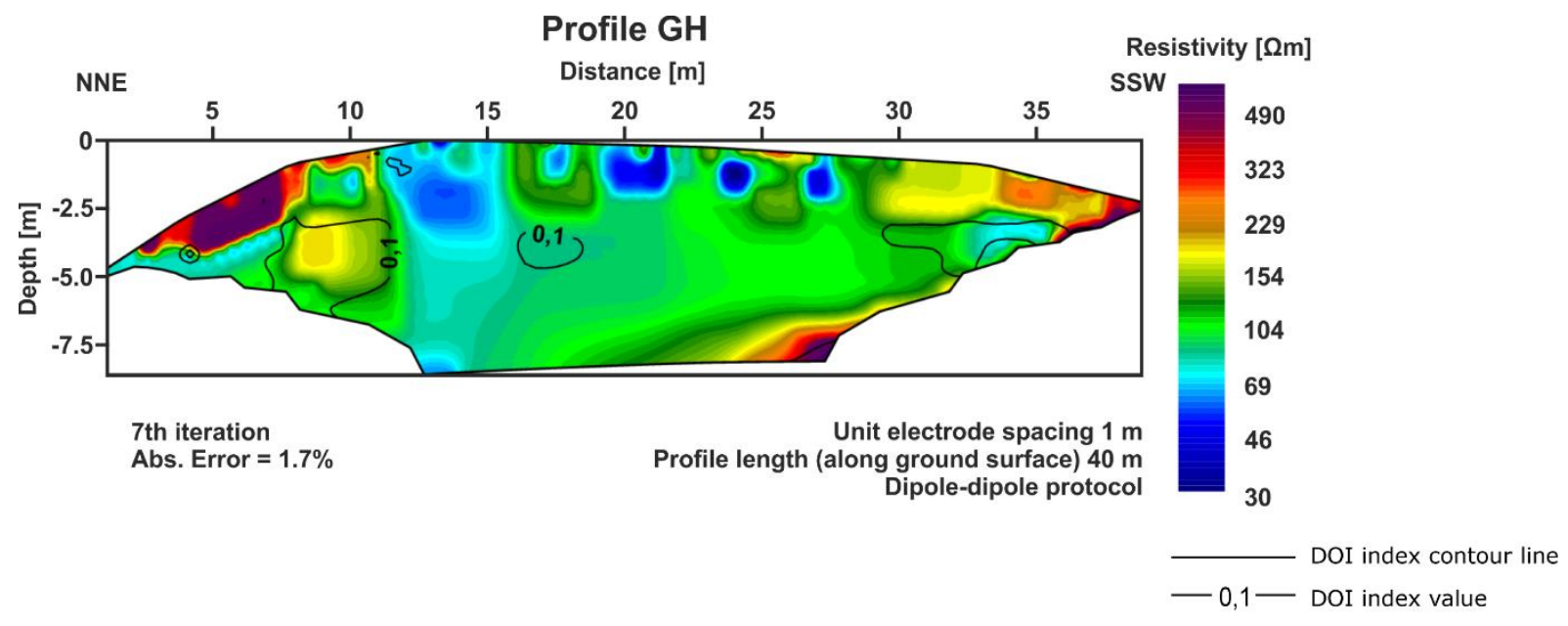

Fig.4. Resistivity cross-section from profile GH, overlapped with DOI index map.

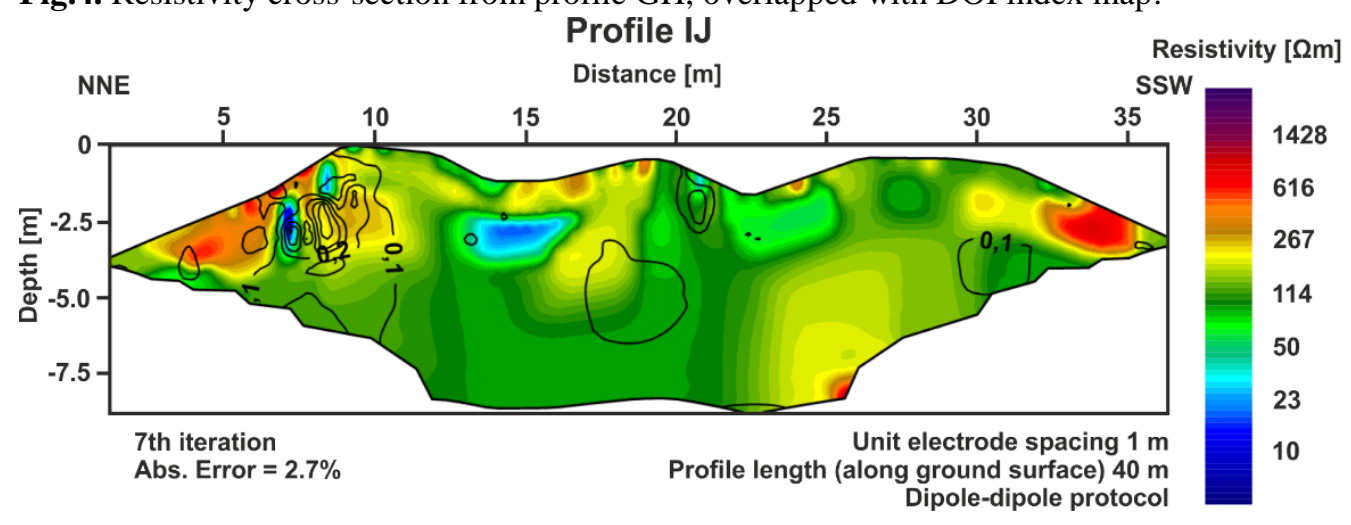

DOI index contour line

- 0.1 - DOI index value

Fig.5. Resistivity cross-section from profile IJ, overlapped with DOI index map. 


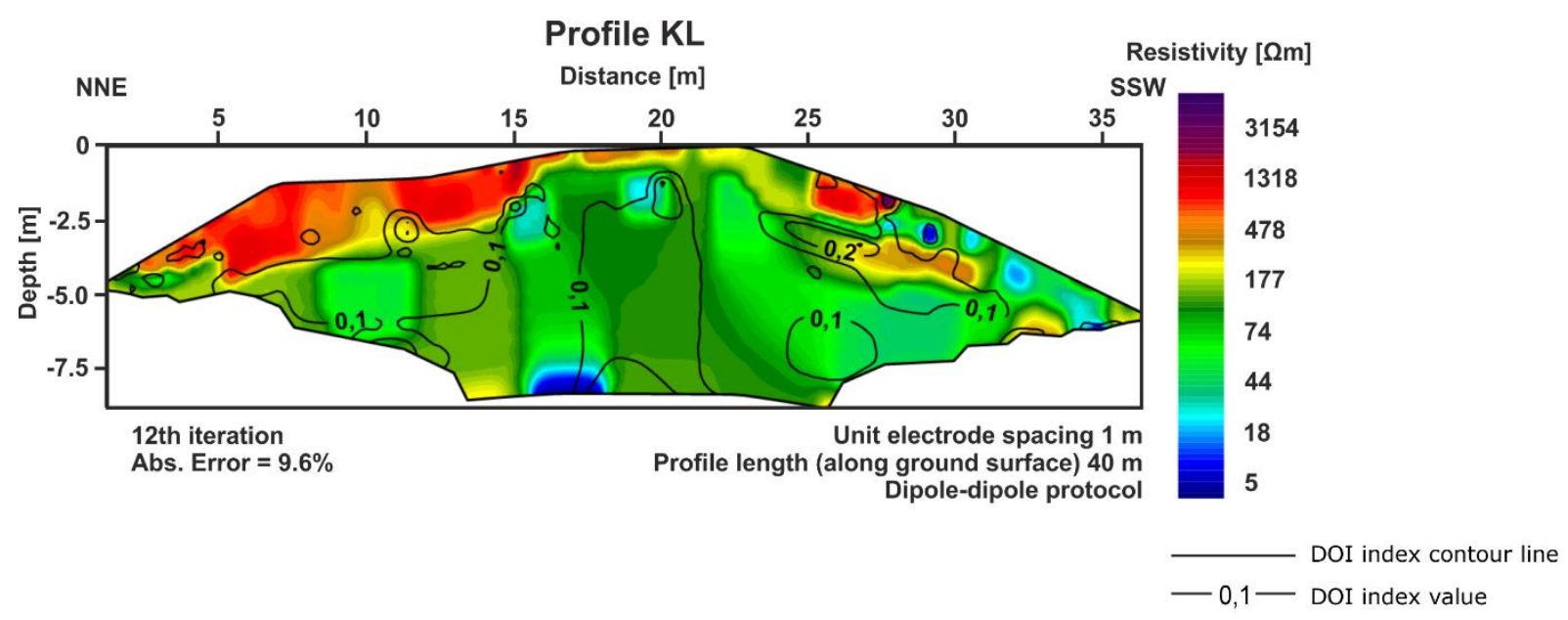

Fig.6. Resistivity cross-section from profile KL, overlapped with DOI index map.

\section{Discussion and conclusions}

Except KL resistivity cross section all generated models are characterized by very low absolute error value. It is an effect of relatively good ground-electrode contact conditions. On profile $\mathrm{AB}$ during the contact electrode test four electrodes showed resistance values by far in excess of average. Unfortunately, electrodes with the bad contact were scattered along the whole profile. To ensure the stability of inversion and low absolute error value over 70 from 524 datum points have been excluded from Schlumberger protocol. Almost half of electrodes on profile KL showed difficulties in stabilization into the ground. On the contact electrode test the acquired average resistance was $1000 \Omega$. But it should be noted that if only first seventeen electrodes would be considered then the average resistance would be around $1500 \Omega$. These conditions limited the quality of obtained data for greater depths and are responsible for systematic error in the measurements. Additionally significantly impedes filtration of useful data. There have been cut off over 40 from 308 measurements from dipole-dipole protocol. Other profiles have not undergone substantial data filtering.

All high resistivity anomalies situated at the top of the slopes of the oval plateau should be considered in terms of remains of the foundations of the ramparts.

On resistivity cross section $\mathrm{AB}$ anomalies in the middle of the ditch surrounding the castle, can be correlated to a rubble of the walls rolled down or, in eastern side, due to the very narrow structure, to a substructure that supported former wooden platform for drawbridge. Considering the overall geological structure, resistivity values up to $100 \Omega \mathrm{m}$ should be correlated to mudstones and claystones while increase in resistivity at the center of profile is probably due to presence of sandstones. With interpreted sandstones there is related a relatively high DOI index value, up to 0.3 . It might be linked to the more complex structure or forced by optimization equation greater resistivity of this complex than requested from most of field data. The second option has its roots in the analysis of the dipole-dipole protocol (not presented) where DOI index maps in those same places jumps out only to 0.1 but resistivity of probable sandstone is lower. Comparing those two electrode arrays this might be associated with the difference in positions of current electrodes imposed on scattered positions of electrodes with the bad contact.

On profiles $\mathrm{GH}$ and $\mathrm{IJ}$ at a depth of $1 \mathrm{~m}$ relatively low resistivity anomalies appear. Their occurrence is hard to explain, whether they come from incorrect measurements, side 
effect of topography change or human made structures filled with high conductive material. But surely on generated IJ model low resistivity anomalies, that occurs at the slope, should be considered as an relict of optimization process as it is proven by the DOI index anomalies up to 0.5 .

Profile KL, despite the absolute error near $10 \%$, from the archaeological point of view is the most important of all. Between $6 \mathrm{~m}$ and $15 \mathrm{~m}$ of profile length almost continuous high resistivity anomaly appears. It can be associated, based on analogy to the similar castle from the same period of time, to fundamentals of the main building of those fortifications.

Deeper resistivity complexes remain uncertain though DOI index application. It means that this index is insensitive to misleading models resulting from systematic measurement errors.

Electrical resistivity tomography proves to be an useful tool in archaeological surveys of castle ruins. It has been suggested to enhance geophysical research for ground penetrating radar which would give final confirmed to unsettled issues and probably would designate sharper boundaries of main building fundaments.

\section{Acknowledgements}

We would like to thank for help:

Vogt of Stryszów Commune, Jan Wacławski for help and support during preparations for performing surveys

Student Science Society of Geophysicist PREM, University of Silesia for their help and companion during field surveys.

\section{Reference}

Caterina D., Beaujean J., Robert T.,Nguyen F., (2013), A comparison study of different image appraisal tools for electrical resistivity tomography. Near Surface Geophysics, 11, 639-657

Czeppe Z., German K., (1981) Physicogeographical regions. [map in:] Atlas of Bielsko - Biala voivodeship, O/PAN, Krakow. [in Polish].

Griffiths, D.H., Barker R.D. (1994) Electrical imaging in archeology, J. Archeol. Sc. 21, p. $153-158$

Kajzer L., Kołodziejski S., Salm J., (2001) Lexicon of castles in Poland, Warszawa, [in Polish].

Kołodziejski S., (1994) Medieval defensive residences of nobles from territory of Krakow voivodeship, Kraków, [in Polish].

Leńczyk G., (1983) Catalogue of gords and castles from Malopolskie voivodeship. Museum of archeology in Krakow p. 17, 39 [in Polish].

Loke M.H. (2014) Tutorial: 2-D and 3-D electrical imaging; surveys in: http://www.geoelectrical.com (Website accessed 26.04.2014)

Loke M.H., Acworth I., Dahlin T. (2003), A comparison of smooth and blocky inversion methods in 2D electrical imaging surveys, Exploration Geophysics 34, p. 182-187

Marescot L., Loke M.H., Chapellier D., Delaloye R.,Lambiel C., Reynard E. (2003) Assesing reliability of 2D resistivity imaging in mountain permafrost studies using the depth of investigation index method, Near Surface Geophysics, 1(2), 57-67

Oldenburg D. W., Jones F.H.M., (2007) Inversion for Applied Geophysics; Learning resources about geophysical inversion, University of British Columbia: Geophysical Inversion Facility, http://www.eos.ubc.ca/ubcgif/iag/index.ht $\mathrm{m}$ (Website accessed 26.04.2014)

Oldenburg D.W., Li Y. (1999) Estimating depth of investigation in dc resistivity and IP surveys, Geophysics 64(2), 403-416. 
Poręba A., Zuberek W.M., Nogaj-Chachaj J., Kotyrba A., Siwek S. (2007) Archaeological objects in loesses recognized by GPR research at the site Karmanowice, Poland Acta Geophysica, vol. 55 , no. 4 , p. $640-651$.

Reyniak J., (1997) Medieval castle Wołek. Preliminary results of research, Teki Krakowskie vol. 4, p. 87-98, [in Polish].

Rudzki M., (2002) Application of electrical resistivity tomography to detect subsurface man-made objects Publis. Inst. Geophys. Pol. Acad. Sc., M-25 (313), [in Polish].

Siemionow A., (1984) Wadowice land, PTTK p. 27, 483 Wadowice [in Polish].

Sikora F., (1980-1986) entry "Barwałd" [in:] Historical and geographical lexicon of Krakow voivodeship in medieval, part. I, Wrocław, p. 24-25, [in Polish]. 